\title{
DESENVOLVIMENTO PROFISSIONAL DOCENTE EM UM GRUPO COLABORATIVO
}

\author{
Paulo Jorge Magalhães Teixeira iD 1
}

\section{Resumo:}

É um desafio escrever sobre formação de professores pela diversidade de correntes de pesquisadores - cada qual defendendo seu espaço político e ideológico-, e pela amplitude de temas que se conectam entre si. Mas, é preciso avançar e levantar novas questões de estudo - como é o propósito deste artigo ao abordar questões no universo da formação continuada de professores, em uma perspectiva críticoreflexiva em um grupo colaborativo, indicado como espaço propício ao desenvolvimento de uma formação continuada. Traz-se à tona as dificuldades, preocupações e concepções de duas professoras recém formadas no exercício de pouco mais de um mês de docência. Trata-se de um estudo qualitativo, no seio de uma pesquisa-ação estratégica, com o lócus dos relatos feitos em um grupo colaborativo já consolidado. A coleta de dados objeto deste recorte foi feita por meio de perguntas dos membros do grupo colaborativo às duas professoras durante o encontro no qual elas se apresentaram, e feitas as primeiras colocações. O estudo mostrou a necessidade de haver participação de professores - principalmente os recém ingressos no magistério - em grupos colaborativos, uma vez que nestes grupos encontram-se ambientes propícios ao desenvolvimento profissional. Nestes grupos as angústias e ansiedades - próprias do início da docência - encontram espaço para serem colocadas, ouvidas e refletidas em conjunto com professores mais experientes, fomentando trocas de saberes, conhecimentos e experiências formativas.

Palavras-chave: Separadas; Por; Ponto e vírgula.

\section{TEACHER PROFESSIONAL DEVELOPMENT IN A COLLABORATIVE GROUP}

\section{Abstract:}

It is a challenge to write about teacher education due to the diversity of researchers' streams - each one defending their political and ideological space - and the breadth of themes that connect with each other. However, it is necessary to advance and raise new study questions - as is the purpose of this article when addressing issues in the universe of continuing education for teachers, in a critical-reflexive perspective in a collaborative group, indicated as a conducive space for the development of continuing education. It brings up the difficulties, concerns and conceptions of two recently graduated teachers in the exercise of just over a month of teaching. It is a

${ }^{1}$ Doutor em Educação Matemática pela UNIBAN - Universidade Bandeirante de São Paulo (2012). Professor Associado do Departamento de Análise, Instituto de Matemática e Estatística, Universidade Federal Fluminense - UFF. Contato: paulojorge@id.uff.br 
qualitative study, within a strategic action research, with the locus of reports made in a collaborative group already consolidated. The data collection object of this cut was made through questions from the members of the collaborative group to the two teachers during the meeting in which they presented themselves, and the first placements were made. The study showed the need for teachers to participate especially those who have just entered the teaching profession - in collaborative groups, since these groups find environments conducive to professional development. In these groups, the anxieties and anxieties - typical of the beginning of teaching - find space to be placed, heard and reflected together with more experienced teachers, promoting exchanges of knowledge, knowledge and training experiences.

Keywords: Beginning of Teaching; Teacher Professional Development; Third Space; Continuing Teacher Education.

\section{Introdução}

O presente artigo é recorte de um estudo inicialmente intitulado "Estudo sobre os conhecimentos necessários ao professor de Matemática para desenvolver e explorar jogos didáticos em consonância com a sua atuação docente em sala de aula com alunos da Educação Básica".

O objetivo central do estudo se pauta em compreender em que medida os conhecimentos relativos ao exercício da docência: conhecimentos de conteúdo, conhecimentos, pedagógicos de conteúdo, conhecimentos curriculares e conhecimentos de tecnologia - desenvolvidos, refletidos e discutidos no seio de um grupo colaborativo -, contribuem para a construção, desenvolvimento e exploração de jogos didáticos que sejam aplicáveis a alunos da Educação Básica.

Para o presente artigo, levantamos a seguinte questão de estudo: "Até que ponto as interações, reflexões e discussões feitas entre integrantes mais experientes e integrantes novatos, em um grupo colaborativo, durante os momentos destinados às considerações, construção e o desenvolvimento de jogos didáticos podem contribuir para o desenvolvimento profissional de todos os membros do grupo?"

Nesse ambiente, e no contexto objeto das discussões acerca dos jogos didáticos, o grupo recebeu a presença de duas professoras recém formadas, com docência nos anos iniciais do Ensino Fundamental. Portanto, professoras em início de carreira que foram pedir ajuda ao grupo para esse início de caminhada em relação ao ensino e aprendizagem de conteúdos de Matemática para alunos do $2^{\circ}$ Ano.

Assim, este recorte relata os resultados da análise de dados relativos ao contato inicial dos membros do grupo com as dificuldades, preocupações e concepções das duas professoras visitantes no exercício de pouco mais de um mês de docência. Trazse à tona a percepção dos membros do grupo colaborativo em relação aos problemas que mais afligiam as professoras e os desafios que são postos à iniciação profissional de todo e qualquer jovem que conclui um curso de graduação - independentemente do tipo de Licenciatura ou disciplina.

Um jovem professor que vai se defrontar com a prática pedagógica diuturna da sala de aula em um ambiente novo, novos colegas de trabalho, ainda inseguro quanto 
aos saberes profissionais, a relação que precisa ter com os alunos e os colegas professores, o ambiente familiar, e outros elementos que contribuem para compor o cenário.

Em seção mais adiante será apresentado um resumo das atividades do grupo colaborativo de modo que o leitor conheça um pouco mais sobre como elas são desenvolvidas, tornando conhecidos as dinâmicas dos encontros e os trabalhos que são preparados e desenvolvidos pelos seus membros.

\section{O início da docência: abordagem teórica}

Pesquisas têm constatado haver necessidade de serem feitos investimentos em programas de formação continuada, notadamente em grupos colaborativos, considerando o cenário atual da formação inicial de professores que vão ensinar Matemática para estudantes do ensino básico e o mercado de trabalho para professores iniciantes.

O propósito principal é o de complementar a formação acadêmica inicial específica do componente curricular do novo profissional de modo a cobrir lacunas formativas e, assim, fortalecê-la.

Para tal, entendemos haver necessidade de estudos para o estabelecimento de um programa formativo consoante 2(duas) vertentes básicas: estudar as principais dificuldades que um recém professor encontra para iniciar na sua atividade profissional docente e identificar o que um programa de formação continuada poderia oferecer a esses profissionais, de modo a ajudá-los a superar tais dificuldades.

É habitual que durante o período de transição de estudante recém graduado e a responsabilidade que o exercício docente impõe, o recém professor constantemente se veja diante de conflitos e tensões próprios dos novos momentos em sua vida.

Beach e Pearson (1998) identificaram alguns conflitos, e os categorizaram em 4 (quatro) tipos, a saber:

- Conflitos curriculares e de instrução: normalmente esses conflitos aparecem logo no início da docência por conta de haver certo embate entre a proposta de trabalho que é apresentada para toda a equipe de professores pela equipe pedagógica da escola/colégio, e os conceitos e teorias que o recém professor teria, em tese, acabado de aprender durante o seu curso de formação inicial;

- Conflitos de posição: são conflitos que se originam pela dualidade entre os embates internos que vêm à tona por conta de divergências entre a necessidade que o recém professor se vê obrigado a construir em relação ao seu novo papel na sociedade que é o de ser, agora, um jovem profissional da educação e não mais um estudante universitário, e a imagem que ele passa a fazer de si mesmo - a sua autoimagem;

- Conflitos decorrentes das relações interpessoais: são entendidos como tensões que estão associadas com a necessidade de ter de construir e preservar relações pessoais com as novas relações que se avizinham por conta da sua nova posição no ambiente de trabalho, no seio da comunidade escolar: alunos, professores, direção, pais e funcionários;

- Conflitos institucionais: são conflitos que surgem por conta dos valores pessoais formativos e as expectativas que cada professor passa a vivenciar no ambiente de trabalho quando se confronta com o trabalho que a instituição espera que seja feito por cada um de seus colaboradores e os limites permitidos, por ela 
própria, para a atuação e a postura de cada um, sob a vigilância indireta dos pais e/ou responsáveis dos alunos (BEACH; PEARSON, 1998).

Uma vez se considere que a docência exige experiências práticas de sala de aula, estas só serão desenvolvidas e consolidadas pelo professor quando do estabelecimento de interfaces entre as teorias estudadas durante a formação inicial e as diferentes realidades nas quais os futuros professores irão atuar.

Assim, as tensões e conflitos os quais Beach e Pearson (1998) referem podem ser enfraquecidas à medida que os recém professores tenham o amparo dos colegas mais experientes em simultaneidade com o caminhar do exercício da docência, principalmente em ambientes dialógicos como os que estão presentes nos grupos colaborativos, por exemplo.

Baseado na teoria do hibridismo, Bhabha (1990, p. 211) considera que os preceitos de "Terceiro Espaço" são dela decorrentes e que no universo escolar é preciso que todos os atores nele envolvidos (docentes, gestores e pesquisadores) se esforcem para uma harmoniosa interação entre si de modo que, juntos, aprimorem a formação docente. $E$, que esse aprimoramento se dê por meio de um aprendizado que leve em conta a prática e o desenvolvimento de pesquisa científica, em áreas de pesquisa do universo da Educação.

Bhabha (1990, p. 211) destaca que o hibridismo não envolve "dois momentos originais dos quais o terceiro emerge" e sim que "o hibridismo é o 'terceiro espaço' que permite que outras posições possam emergir". Segundo esse conceito, o "Terceiro Espaço" é o "espaço apropriado" para o estudo de novas teorias, novas práticas, novas posturas e novos olhares em relação às antigas práticas de ensinar e aprender que já se conhecem. Também é preciso que isto se dê por meio da troca de experiências, reflexões, participação, observação, experimentação, desenvolvimento e apropriação de saberes docentes.

No entender de Zeichner (2010), o conceito de "Terceiro Espaço" se caracteriza pela rejeição à oposição entre o saber acadêmico e o saber da prática, por conta de considerar que estes saberes não são modos de discursos antagônicos e concorrentes (em competição), mas que estão em sintonia (em conformidade) e em sincronia (haver simultaneidade de acontecimentos ou fenômenos).

Por conta disso, no decorrer de uma longa carreira, como é o caso do magistério, o exercício da docência cobra do professor que ele adquira experiência prática para o trabalho do dia a dia, na sala de aula e fora dela, de modo que a interface entre a teoria da formação inicial e a prática, vá se consolidando com a(s) realidade(s) da prática docente que ele experimenta.

Mas, para que isso se dê de maneira mais suave desde os primeiros anos de docência, será preciso que o professor vá aprendendo a diminuir as tensões e os conflitos que Beach e Pearson (1998) identificaram. Também, que estejam em consonância com o conceito de "Terceiro Espaço" levando em conta o que Zeichner (2010) entende deva ser, como apresentado acima.

Então, como um professor pode aprender com tudo isso, ao longo de uma carreira de muitos anos de prática docente? Entendemos que a(s) escola(s) em que o professor trabalha e o(s) coletivo(s) junto de seus pares seja(m) o(s) espaço(s) mais próximo(s) da(s) realidade(s) de atuação docente onde um grupo colaborativo pode nascer. 
Assim, é preciso que no dia escolar se priorize o menor número de discussões acerca de atividades burocráticas em troca de um número bem maior para travar discussões pedagógicas e curriculares. Entendemos que deve ser esta a marca de atuação de um coletivo escolar, o qual precisa primar por discussões, reflexões e tomada de decisões coletivas em contínuo e amplo processo dialógico que deve se estender para além dos muros da escola.

É preciso que o professor aprenda com as experiências e os conhecimentos de outros colegas professores, mormente os saberes vindos da academia, em formações continuadas.

Contudo, o professor não pode negligenciar na tarefa de sempre fazer leituras acerca de experiências para melhor realizar suas tarefas docentes e participar de encontros, jornadas ou congressos para trocar experiências com colegas, aprender, ensinar, refletir e discutir.

\section{Os sujeitos do estudo e o tipo de estudo}

Escreva O Quadro 1, a seguir, mostra um resumo de parte do perfil pessoal, acadêmico e profissional das 2(duas) professoras recém chegadas ao grupo, ambas concluintes da Licenciatura em Pedagogia, modalidade magistério, ao final de 2019.

Quadro 1: Perfil pessoal, acadêmico e profissional das duas professoras

\begin{tabular}{|c|c|c|c|c|c|c|}
\hline Professora & Idade & $\begin{array}{c}\text { Turma } \\
\text { que } \\
\text { leciona }\end{array}$ & Docência & $\begin{array}{c}\text { Instituição } \\
\text { formativa }\end{array}$ & $\begin{array}{c}\text { Processo } \\
\text { de seleção }\end{array}$ & $\begin{array}{c}\text { Trabalho } \\
\text { anterior }\end{array}$ \\
\hline P1 & 23 & 20 Ano & $\begin{array}{c}\text { Menos de } \\
2 \text { meses }\end{array}$ & $\begin{array}{c}\text { Faculdade } \\
\text { privada A }\end{array}$ & $\begin{array}{c}\text { Entrega de } \\
\text { currículo }\end{array}$ & Não \\
\hline P2 & 24 & 20 Ano & $\begin{array}{c}\text { Menos de } 2 \\
\text { meses }\end{array}$ & $\begin{array}{c}\text { Faculdade } \\
\text { privada B }\end{array}$ & $\begin{array}{c}\text { Entrega do } \\
\text { currículo }\end{array}$ & Não \\
\hline
\end{tabular}

Fonte: o autor (2020).

O Quadro 1, acima, mostra parte do perfil pessoal, acadêmico e profissional das duas professoras, e nele é possível identificar semelhanças em quase todos os itens. As professoras relataram que as experiências de sala de aula decorrentes do período de estágio supervisionado com alunos dos anos iniciais do Ensino Fundamental, resumiram-se ao acompanhamento de aulas apenas, e que não escreveram um trabalho de conclusão de curso como é habitual.

De início os membros do grupo pensaram em programar uma formação continuada conforme os momentos de atuação e ações, já traçados pelo grupo, segundo as atividades habituais. Mas, para que isso acontecesse seria preciso fazer um planejamento de atividades que desse conta de encaminhar as reflexões e discussões com as professoras a partir da identificação das suas inquietações.

Por sua vez, tais inquietações também iriam perpassar a atuação docente cotidiana das professoras, o que se configuraria como reflexões feitas sobre algo que já teria ocorrido e o que queríamos era antecipar situações/problemas para que não ocorressem ou se saídas já tivessem sido pensadas.

Por conta dessa hipótese de trabalho, consideramos que o estudo teria seus objetivos assentados no propósito de contribuir, de maneira objetiva, para a (re) significação de uma prática pedagógica que pudesse ser pensada pelas professoras 
à luz dos conhecimentos teóricos que possivelmente teriam estado presentes durante a formação inicial.

Além do mais era preciso transformar a realidade a qual as professoras se encontravam, conhecer as inquietações e problemas que as afligiam, e buscar soluções para acalmá-las e para os problemas colocados para reflexão.

O fato é que "trabalhar com professores iniciantes requer o entendimento de que a constituição da prática pedagógica implica uma articulação de saberes relativos às situações com os quais o docente se confronta". (CIRÍACO, MORELATTI e PONTE, 2019, p. 53)

Para tal, tomamos conceitos defendidos por Hargreaves (1998) segundo a cultura da colaboração. No que refere ao campo da formação e prática pedagógica, é preciso afirmar a necessidade de tomar a reflexão como elemento estruturante dos conhecimentos profissionais dos professores a partir da cultura da colaboração (HARGREAVES, 1998).

Todos devem estar imbuídos dos mesmos propósitos.

Assim, consideramos que o planejamento feito está em consonância como o que está presente em uma "pesquisa-ação estratégica", segundo Franco (2005). Pesquisa estratégica, no sentido de que é preciso estabelecer os caminhos que culminem no propósito de encontrar soluções coletivas que favoreçam a superação das inquietações e dificuldades das professoras de modo efetivo - legítimas que são, mormente no início da carreira docente.

É preciso enfrentar os problemas e procurar caminhos para solucioná-los. Para isso, diferentes estratégias têm de ser pensadas, testadas, colocadas em ação com alunos reais e, em seguida, avaliadas.

Em parte, essa opção se deve ao fato de as professoras não terem experiências pedagógicas consolidadas e conhecimentos de conteúdo de Matemática fundamentados, mas precisam aprender para ensinar e ensinar para aprender. Sobre essa questão

É preciso que, pelo contrário, desde os começos do processo, vá ficando cada vez mais claro que, embora diferentes entre si, quem forma se forma e reforma ao formar e quem é formado forma-se e forma ao ser formado. É neste sentido que ensinar não é transferir conhecimentos, conteúdos, nem formar é ação pela qual um sujeito criador dá forma, estilo ou alma a um corpo indeciso e acomodado. Não há docência sem discência, as duas se explicam e seus sujeitos, apesar das diferenças que os conotam, não se reduzem à condição de objeto um do outro. Quem ensina aprende ao ensinar e quem aprende ensina ao aprender. Quem ensina ensina alguma coisa a alguém. É por isso que, do ponto de vista gramatical, o verbo ensinar é um verbo transitivo relativo. Verbo que pede um objeto direto - alguma coisa - e um objeto indireto - a alguém. (FREIRE, 2013, p. 25)

\subsection{A chegada de duas professoras ao grupo colaborativo}

No início de 2020, a primeira reunião do grupo colaborativo denominado Observatório de Educação Matemática (OBSEM) foi realizada em 13 de fevereiro. Nessa ocasião, o grupo colaborativo era formado pelo autor deste artigo, o coordenador do grupo, e duas professoras - ambas com Licenciatura em Matemática. Tais professoras já fazem parte do grupo colaborativo OBSEM a dois anos, e ensinam Matemática para turmas dos anos finais do Ensino Fundamental. Neste dia de 
reunião, 13 de fevereiro, o grupo colaborativo teve o prazer de contar com a presença de duas professoras recém graduadas em Licenciatura em Pedagogia - consideradas sujeitos de estudo, para os fins deste recorte.

A reunião seguinte ocorreu em 5/3/2020, após o carnaval. Mas, devido a pandemia, não tivemos nenhuma outra reunião presencial, mas apenas por meio de contatos virtuais via telefone ou encontros por meio de "lives". Nestes contatos as professoras informaram que as aulas haviam sido suspensas ao final do dia 13 de março, não retornando até a data em que este artigo foi escrito: 17 de julho.

É habitual que a dinâmica de boas-vindas ao grupo se inicie com um dos membros fazendo um relato de como foi a trajetória do grupo; os objetivos do trabalho que está sendo desenvolvido no momento; as expectativas de novos trabalhos e como cada um contribui para o desenvolvimento das atividades, 0 fortalecimento das ações e a defesa dos propósitos.

Aos recém ingressos é dito que fiquem a vontade para explanar as suas experiências acadêmicas desde quando eram estudantes da Educação Básica, durante o curso de formação inicial de professor, o curso de graduação, bem como em relação às experiências profissionais, se for o caso. No OBSEM não há um material tipo questionário/entrevista com indagações para submeter aos novos membros ou aos professores e/ou alunos que nos visitam.

No caso das duas recém-chegadas professoras ao grupo, seria preciso ouvir atentamente as suas angústias, inquietações e razões que as levaram a procurar o grupo. Em prosseguimento os membros do grupo teriam de identificar se teriam condições de ajudá-los a enfrentar os desafios do exercício da docência, e como poderiam fazer isso.

Ou seja, foi preciso que todos os membros do grupo avaliassem se o grupo teria condições de contribuir com o trabalho docente que as professoras precisariam desenvolver; se a participação das professoras iria limitar-se à ajuda que o grupo poderia emprestar-Ihes ou não. $E$, se fosse o caso de as professoras terem tempo e interesse, que tipo de atuação elas poderiam emprestar aos trabalhos que estão em andamento.

Fato é que todos os membros do grupo tem a responsabilidade coletiva de saber ouvir os colegas e, a partir daí, refletirem coletivamente no sentido de identificarem os problemas que afligem a cada um individualmente e como o grupo pode ajudar.

Portanto, seria preciso verificar em que medida o grupo poderia contribuir para que as professoras possam enfrentar os desafios que se impõem diariamente à atuação docente, sejam jovens professores recém formadas ou não.

No seio do grupo as práticas docentes de sala de aula de seus membros são repartidas e discutidas, os progressos e os fracassos, e soluções para diversas situações são sempre procuradas, no sentido de contribuir para que cada colega reflita acerca das possibilidades que tem para resolver 0 seu particular problema/situação e tomar as decisões que julgue pertinentes.

De modo que o leitor conheça um pouco acerca das atividades que o grupo desenvolvia até a chegada das 2(duas) professoras recém formadas, em prosseguimento faremos um resumo de como é a dinâmica dos trabalhos que são desenvolvidos no grupo colaborativo OBSEM - Observatório de Educação Matemática, e logo em seguida voltamos à questão objeto do presente artigo. 


\subsection{0 grupo colaborativo OBSEM}

O OBSEM é um grupo colaborativo formado por professores que ensinam Matemática na Escola Básica, professores de ensino Superior, estudantes em formação inicial em Licenciatura em Matemática e Licenciatura em Pedagogia, e professores em formação continuada. O OBSEM foi criado em Fevereiro de 2014 pela iniciativa de três professores docentes da Universidade Federal Fluminense (UFF), mas apenas o autor deste artigo ainda permanece no grupo. À época, o OBSEM não estava vinculado a um projeto institucional de ensino e/ou pesquisa da universidade em que os seus fundadores desenvolvem projetos de ensino, pesquisa e extensão. Surgiu por conta de inquietações pessoais, que efervesceram a ponto de torná-lo necessário e factível. Os três professores fundadores atuavam à época como docentes de disciplinas de um Curso de Especialização em Ensino da Matemática, que ainda hoje é oferecido pela UFF.

O propósito do grupo é refletir, discutir, realizar estudos e fazer pesquisas concernentes ao ensino aprendizagem da Matemática para a Educação Básica com vistas a oferecer contribuições para a melhoria desses processos.

Em uma dimensão mais abrangente todo o trabalho do grupo visa contribuir para que o professor melhore os processos de comunicação com seus alunos e dos alunos com o seu professor, durante as aulas de Matemática. Para tal, salientamos a necessidade de o professor aprofundar estudos acerca dos mecanismos pedagógicos que o levem a melhorar o diálogo entre eles.

Também objetiva disseminar ideias que levem ao desenvolvimento da leitura e da escrita em Matemática considerando a importância que emprestamos a essas habilidades - indispensáveis que são para alcançar tais objetivos.

O OBSEM não conta com a ajuda de órgãos governamentais ou de instituições públicas ou privadas. Tampouco tens fins lucrativos. O OBSEM tem o propósito de contribuir com o ensino e aprendizagem da Matemática na Escola Básica. No momento, todo o trabalho da equipe do OBSEM é desenvolvido em uma sala de aula cedida por uma instituição de ensino filantrópica religiosa, e por meio de comunicações on-line entre os membros.

As reuniões do grupo são semanais, com duração de 3 horas cada, fora do horário escolar da instituição: das 17:30 às 20:30h. A atuação do OBSEM também se desenvolve pelos diálogos e a elaboração de materiais em ambientes virtuais, nos quais os membros trocam experiências e conhecimentos entre si e relatam estudos, pesquisas e resultados de experiências.

Todo o material pedagógico que até então tem sido preparado pelo grupo, nasceu e continua a nascer das inquietações pessoais e coletivas dos membros do grupo. Tais inquietações levam os membros do grupo a fazer estudos e a realizar pesquisas, de modo a formular e fundamentar perguntas de estudo e questões de pesquisa, que advém daí. Em retorno à aplicação das atividades preparadas pelos membros do grupo e outras que possivelmente surgem no decorrer das experiências formativas, por vezes novas perguntas são levantadas pelos que participam dos encontros.

Tais perguntas podem estar em conexão com a temática em estudo ou não. Por conta disso, elas demandam novas investigações, em um processo cíclico contínuo de idas e vindas. 
A dinâmica das atividades do grupo, embora variáveis, ao sabor das questões postas em discussão por qualquer um de seus membros e demandas externas, em um processo cíclico, guarda entre si ações colaborativas que não deixam de ser consideradas.

Em destaque, as seguintes:

1. Uma pergunta, uma questão, um problema ou uma proposta é colocada para o grupo de modo que, em um processo dialógico conjunto, o grupo identifique se há possibilidade/interesse de considerar as variáveis, e seguir em frente;

2. Uma vez que uma questão, um problema ou uma proposta seja considerada pertinente, ela é colocada em discussão para a reflexão de todos. Como o grupo pode se debruçar em estudar a questão? Quais as fontes de pesquisa? Quais as ações necessárias, e como cada membro pode contribuir para o encaminhamento do estudo (ou problema colocado)? O membro terá disponibilidade, interesse e condições de se envolver? De que modo?

3. Uma vez que o grupo tenha estudado e discutido certa questão, os membros têm condições de implementar/desenvolver uma sequência didática, atividade ou jogo didático que contribua para a solução? Como reunir as ações e considerações defendidas pelo grupo? As ações requerem validação de hipóteses, que precisam ser lançadas. É preciso estabelecer hipóteses iniciais, fazer implementação prévia e testar. Como fazer? Após testar, as hipóteses mostraram-se adequadas? Como as hipóteses serão validadas a priori? Como será o trabalho de campo? Que atividades serão necessárias organizar? No trabalho de campo, novas questões foram levantadas? Quais? A análise dos dados colhidos mostrou-se adequada com a hipótese prévia?

4. É preciso que todo o grupo se debruce em analisar os dados coletados, e também promover discussões coletivas e reflexões acerca da análise dos dados e dos resultados obtidos;

5. Como será feita a apresentação dos resultados? O estudo resultou em informações que mereceriam a escrita de um artigo? Se sim, o que é preciso informar e relatar?

Assim, os membros do grupo são constantemente desafiados a estudar e a pesquisar tanto em relação aos recursos que podem/devem ser mobilizados para a construção de atividades quanto ao modo correto e adequado para atender necessidades que visam encontrar e encurtar caminhos que levem à obtenção de respostas para os estudos que estão sendo desenvolvidos.

São conceitos próprios à constituição e o desenvolvimento de um grupo colaborativo, como entendemos ser a atuação do OBSEM.

O autor sempre lembra aos membros do grupo que recorram às sábias palavras do poeta João Cabral de Melo Neto, presentes em seu poema "Tecendo a Manhã", que aproxima as razões para a existência do grupo colaborativo, em estreita relação com uma programação que se destina a atender a formação continuada de professores.

Assim, relembra que as ações do grupo precisam ser pensadas, discutidas, refletidas e elaboradas e aos poucos ir se consolidando nas falas e ações dos diferentes atores envolvidos nos projetos que sustentam as diferentes questões de estudo. 
Questões as quais os membros do grupo precisam se debruçar considerando a abrangência de seus propósitos e as subjetividades de cada um. Eis o poema "Tecendo a Manhã":

Tecendo a Manhã:

Um galo sozinho não tece uma manhã/ ele precisará sempre de outros galos De um que apanhe esse grito que ele/ e o lance a outro; e de outros galos/ que com muitos outros galos se cruzem/ os fios de sol de seus gritos de galo,/ para que a manhã, desde uma teia tênue,/ se vá tecendo, entre todos os galos/ e se encorpando em tela, entre todos,/ se erguendo tenda, onde entrem todos,/ se entretendendo para todos, no toldo/ (a manhã) que plana livre de armação./ A manhã, toldo de um tecido tão aéreo/ que, tecido, se eleva por si: luz balão (MELO NETO, 1966, p. 1).

Entendemos que, em um objetivo mais amplo, cada membro do grupo dispõese a contribuir para o aprimoramento e o desenvolvimento de processos educativos que visam melhorar o ensino e aprendizagem da Matemática na Educação Básica razão precípua de fazer parte do grupo.

Pois, um membro do grupo também é um professor que atua próximo aos professores que ensinam Matemática, em exercício profissional, e com futuros professores que irão ensinar Matemática na Educação Básica.

\section{As primeiras reações: das duas professoras e dos membros do grupo. Resultados e discussões}

Ao receber as professoras e ouvir as razões que as levaram até o grupo foi preciso implementar uma dinâmica de grupo que implicava em ouvir as inquietações das duas professoras; conhecer as vertentes formativas; levantar questões, e encaminhar reflexões e discussões.

Ou seja, entendemos que seria preciso problematizar em cima das questões levantadas e buscar soluções coletivas com o propósito de, juntos, encontrarmos caminhos para a superação das inquietações.

Tanto no que refere às questões associadas com os conhecimentos de conteúdo, quanto em relação às questões de conhecimentos pedagógicos de conteúdo e posturas atitudinais.

O foco das perguntas do grupo às duas professoras foi o de compreender como elas chegaram até o grupo; quais problemas estavam enfrentando, e o que esperavam do grupo em relação às questões relatadas.

Uma vez que as professoras estavam no grupo, cabia identificar os principais problemas que elas enfrentavam no exercício docente de modo a saber como o grupo poderia ajudá-las sem comprometer os projetos que estavam em andamento.

Os membros do grupo mostraram-se sensíveis às questões que foram postas pelas professoras, e em um primeiro momento, apenas as ouviram.

Com a experiência docente que acumularam, após muitos anos de docência, os membros do grupo sabem bem o quão difícil são os primeiros dias de um professor em um ambiente escolar.

O contato inicial com a prática de sala de aula, o fato de os alunos já estarem habituados à escola - no mínimo estão a um ano estudando nela; o fato de serem professoras novatas, as primeiras experiências no trato com os colegas professores, 
o receio no falar e no emitir opinião, o medo ao atuar, e outros elementos de cunho pessoal.

As professoras chegaram ao grupo por indicação de colegas da escola, após os primeiros dias de trabalho. Ressalte-se que a escola em que as professoras trabalham é a mesma onde o grupo colaborativo realiza os encontros, mas nenhum de seus membros atua como professor nesta escola. E desde que foi criado, o grupo nunca contou com professores dos anos iniciais do Ensino Fundamental.

Os colegas das professoras indicaram o grupo por terem conhecimento da sua existência como um grupo de professores de Matemática que desenvolve atividades na área, uma vez que nenhum dos professores que trabalha na referida escola teve algum contato com qualquer dos membros do grupo.

É certo que o grupo terá de se reestruturar para atender às solicitações demandadas das duas professoras. Precisa reservar um tempo nos encontros para que todo o grupo possa se debruçar com questões exclusivas das professoras.

Assim, será preciso estudar a melhor maneira como as dinâmicas de trabalho colaborativo devem ser implementadas tomando por base o programa de Matemática estipulado pela coordenação pedagógica da escola, que atende os alunos do 20 Ano do Ensino Fundamental - turmas em que as professoras atuam, com 2 (duas) turmas cada uma, nos dois turnos de aulas.

Será preciso que o grupo estude possíveis atividades que já tenham sido desenvolvidas pela coordenação pedagógica para serem desenvolvidas com os alunos - ou, que ainda pretende preparar -, e faça um estudo acerca das orientações presentes na Base Nacional Comum Curricular (BNCC) para este particular segmento de ensino.

Assim, será preciso que os membros do grupo estudem, reflitam e discutam no coletivo a respeito de questões que venham a ser colocadas pelas duas professoras de modo que o grupo contribua de fato para ajudá-las a superar suas dificuldades, e permitir que elas fiquem confiantes para o exercício da docência.

São pontos que precisam ser conhecidos e negociados com as duas professoras e o restante do grupo, pois tudo é muito novo tanto para as professoras quanto para os outros membros do grupo.

No primeiro encontro, foi pedido que as professoras trouxessem tudo aquilo que julgassem conveniente ser avaliado e estudado no grupo, não dispensando: a programação de conteúdo que seria desenvolvido com os alunos já no primeiro bimestre letivo; a quantidade de aulas de Matemática semanais; todo o material pedagógico que já estaria pronto na escola, para ser desenvolvido com os alunos, e a relação do material concreto que poderia ser utilizado com os alunos.

Além do mais, todos os endereços eletrônicos e telefones dos membros do grupo foram disponibilizados para as professoras, com o propósito de facilitar a comunicação e antecipar situações inadiáveis.

Os membros do grupo foram unânimes em sugerir que as professoras convidem outras colegas de trabalho da escola para que fizessem parte do grupo, ou que ao menos pudessem estar presentes no próximo encontro de modo a enriquecer as reflexões e discussões relativas às boas vindas para as novas professoras.

Entendemos que configura-se importante a participação de outras colegas de trabalho nas reflexões e discussões, na medida em que podem partilhar conhecimentos e experiências pessoais da docência no segmento de ensino anos iniciais do Ensino Fundamental. 
Por certo que os relatos que as professoras mais experientes venham trazer irão contribuir para as reflexões do grupo no sentido de unir esforços no sentido de encontrar soluções para o aprimoramento da prática pedagógica das novas professoras e ajudá-las no caminhar da docência, bem como subsidiariam o grupo com novas informações e conhecimentos.

Consideramos essas ações como parte determinante e indispensável para que o grupo reúna condições de avaliar, programar e implementar ampla formação continuada, e que atenda às necessidades das duas professoras novatas, cujo início da formação considera-se já ter sido dado a partir daí: a procura do grupo.

Em prosseguimento, apresentamos algumas perguntas/questões que foram feitas/colocadas às duas professoras, pelos membros do grupo e de modo espontâneo, sem que algo pré-determinado ou com intenção clara tenha sido feito que não as que surgiram no calor das reflexões coletivas. Não apresentamos a totalidade de todas as perguntas/questões por conta do espaço destinado aqui.

Entendemos que as perguntas e as respectivas respostas das duas professoras, nos dão um norte do quão preparado o grupo precisa estar de modo a compreender as dificuldades que as professoras têm e como é possível contribuir para que essas dificuldades possam ser minimizadas, suavizadas e estancadas.

Uma vez que esses dados de estudo ainda são preliminares, a análise deles será feita de modo geral nas considerações finais, as quais serão apresentadas na seção logo a seguir a elas.

a) O que você acha a respeito do conteúdo de Matemática que deve ser ensinado aos alunos do $2^{\circ}$ Ano do Ensino Fundamental, neste $1^{\circ}$ bimestre?

P1: Me parece que não terei dificuldades. Não que eu tenha aprendido na faculdade essas coisas, mas porque são assuntos fáceis de entender e ensinar. P2: O que é pra ensinar não foi o que eu aprendi na faculdade. É simples, fácil.

b) O período do seu estágio foi suficiente, satisfatório e adequado ( ) sim; ( ) não; ( ) talvez, no sentido de preparar você para ensinar? Comente.

P1: Meu estágio foi feito em 3 escolas, um pouco em cada uma, mas eu só assistia às aulas, anotava alguma coisa interessante, e só. Nunca eu dei uma aula, nem mesmo na faculdade.

P2: Eu passei quase um ano letivo assistindo aulas em uma mesma escola, em turmas diferentes do $10,2^{\circ}$ e $3^{\circ}$ Anos, pois nessas turmas eu assistia aulas de matemática, português, ciências etc. Eu assistia as aulas e anotava o que a professora ensinou naquela aula e, todo mês eu entregava ao meu professor de estágio essas anotações, junto com a folha que registrava a minha presença nas aulas, com a assinatura da professora.

c) Você acha que o fato de saber resolver problemas de Matemática é suficiente para ensinar o conteúdo de Matemática aos alunos dos anos iniciais do Ensino Fundamental?

P1: Bem, eu acho que ajuda sim. Como eu sei fazer, vou ensinar aos alunos a fazer como eu resolvo, e eles vão aprender. Eles vão resolvendo as questões da mesma maneira que eu ensinar, mas vou repetir se necessário, se algum aluno não entender.

P2: Eu sei resolver os problemas e as contas, mas as vezes eu me enrolo para ensinar aos alunos como eles precisam fazer. Ainda não tenho muita segurança

Perspectivas em Diálogo, Naviraí, v. 6, n. 16, p. 25-40, jan./abr. 2021. 
em ensinar como eles podem resolver, porque eles são muito rápidos e logo querem saber se acertaram e aí eu fico toda perdida.

d) Você conhece os "Blocos Lógicos" e o "Ábaco"? Aprendeu a trabalhar com esses materiais na faculdade?

P1: Teve uma aula que o professor levou os blocos lógicos, e fizemos algumas atividades. É aquele jogo que tem peças em madeiras pintadas, não é? O ábaco eu não conheço.

P2: Eu conheço os blocos lógicos, mas não tive nenhuma aula para ensinar como se deve usá-lo para ensinar. Eu vi em uma sala na escola que fazia estágio, mas não assisti nenhuma aula que fizesse uso dele. O ábaco eu não conheço, e não lembro de alguém ter dito esse nome de jogo na escola que fiz o estágio.

e) Você tem livros ou apostilas do seu curso de Pedagogia que podem ajudá-la a preparar suas aulas?

P1: Eu tenho apostilas, mas elas tem pouca coisa. Na faculdade não foram muitas as aulas de matemática que tivemos. Livros de matemática eu não tenho não, e quando eu tenho dúvidas eu acesso a internet e vou procurar sobre o assunto. Até acho brincadeiras legais, que eu vou trazer para os alunos. P2: Não tenho apostilas ou livros de matemática. Só o livro de matemática que eu estou usando agora com os meus alunos, e que a escola me deu. Nem lembro do nome dele. Faz pouco tempo que eu o recebi. Também recebi os livros das outras matérias do $2^{\circ}$ ano. Quando eu posso, eu assisto vídeos na internet.

f) Você leu, inteiramente, algum livro sobre Educação, durante o seu curso de Pedagogia?

P1: Não, não li. Só algumas folhas que os professores distribuíam para a gente ler em sala, e discutir depois.

P2: Não, não li. A mesma coisa que a P1.

g) Você tem algum livro sobre Educação em sua casa, e que tenha lido pelo menos alguma parte dele?

P1: Não, não tenho.

P2: Não, não tenho.

h) Dentre os autores Paulo Freire, D'Ambrosio, Tardif, Imbernón e Perrenoud, qual(is) foi(ram) o(s) que você leu algum trecho ou fez algum trabalho na faculdade?

P1: Só de Paulo Freire eu li alguma coisa, mas não fiz trabalho.

P2: Eu li trechos de Paulo Freire e de D'Ambrosio em folhas de papel que os professores distribuíram para a gente ler e discutir em grupos.

i) Você tem, em sua casa, algum livro sobre Educação Matemática ou algum artigo científico sobre alguma pesquisa em Educação Matemática e que tenha lido pelo menos alguma parte? 
P1: Não, não tenho. Não, não tenho.

P2: Não, não tenho. Não, não tenho.

De modo geral, as respostas das duas professoras - como mostrado acima evidenciam lacunas na formação inicial, mas que podem ser superadas ao longo da prática docente considerando o interesse que elas têm demonstrado desde os primeiros dias de magistério, e a disponibilidade de procurarem ajuda.

As lacunas dizem respeito aos conhecimento de conteúdo matemático, conhecimentos pedagógicos de conteúdo e conhecimentos curriculares. Esses conhecimentos são apropriados, desenvolvidos e postos em prática durante a longa carreira de um professor. A cada dia o professor aprende para ensinar e ensina para aprender. Os seus alunos alimentam e retroalimentam a sua prática, em um exercício contínuo.

\section{Considerações finais}

Considerando as perguntas e respostas (presentes acima) que os membros do OBSEM fizeram às duas professoras novatas - os sujeitos do estudo - e os depoimentos iniciais que elas traziam para o grupo em relação às suas inquietações naquele momento, foi possível fazer uma análise geral acerca da problemática envolvida e das dificuldades que as afligiam. Possivelmente, tais dificuldades e inquietações sejam as mesmas que muitos professores recém formados, Brasil afora, também passam.

Não obstante, as professoras terem recebido da escola onde iniciavam a carreira docente, os mesmos livros didáticos que seus alunos irão utilizar durante o ano letivo, ficou-nos perceptível o pouco e mais amiúde apoio pedagógico que poderia vir por parte da coordenação pedagógica. Também o pouco interesse que teria sido demonstrado pelos colegas professores mais experientes, em relação às necessidades pessoais de cada uma delas no tocante à ajuda relativa às lacunas deixadas da formação inicial. De modo geral, essas necessidades são próprias de quem chega a um local de trabalho novo, e não porque se tratava apenas do primeiro ambiente escolar profissional das duas professoras.

Além do mais ficou claro que naquele momento as duas professoras não dispunham de outras fontes bibliográficas que as ajudassem a aprofundar estudos que viessem contribuir para o preparo das suas aulas, que apenas o livro didático que receberam da escola no início do ano letivo. Ressalte-se que o livro didático é o mesmo que os seus alunos vão utilizar durante todo o ano letivo.

Acreditamos que possivelmente deve haver mais livros na biblioteca da escola que podem constituir-se de fonte de pesquisa e estudo pelas professoras - tanto em relação ao conteúdo matemático em si, quanto em relação às práticas pedagógicas relacionadas com o conteúdo que elas precisam lecionar.

Primeiramente, parece-nos que faltou apoio mais amiúde às duas professoras no tocante às necessidades de serem ouvidas pela coordenação pedagógica e os colegas professores, de modo que pudessem se sentir bem mais à vontade no ambiente de trabalho, junto com os seus pares. Também, em fazer colocações relacionadas com as inquietações, angústias e dificuldades que afligiam a cada uma - ao menos nos primeiros dias de docência.

Tal cenário reforça a importância que emprestamos à necessidade de fomentar a criação de grupos colaborativos já no interior das escolas entre a coordenação 
pedagógica, os professores, e os seus pares. Nesses grupos já teríamos uma recepção mais calorosa e próxima dos novos colegas de trabalho; uns e outros conhecer-se-iam melhor; poderiam ser trocadas informações pessoais e de trabalho; laços de confiança podiam ser estreitados, e os colegas poderiam repartir entre si conhecimentos, práticas docentes, experiências pedagógicas e materiais instrucionais, por exemplo.

Em um universo mais amplo, reforçar a importância de formar grupos colaborativos que agreguem professores de universidades, professores da Educação Básica e estudantes em formação inicial nas licenciaturas de Matemática e de Pedagogia.

Nos grupos colaborativos cabe o exame acerca do que os professores em início de carreira conhecem; sobre "o que" e "como" pensam acerca da carreira; sobre questões acerca do ensino e a aprendizagem da Matemática, e acerca da transposição didática de conteúdos matemáticos para o ensino - tanto no Ensino Fundamental quanto no Ensino Médio. Os grupos colaborativos são perfeitamente apropriados para essas finalidades.

Julgamos que é preciso que se estabeleça um ambiente propício ao desenvolvimento profissional de professores por meio do engajamento de seus membros em diferentes projetos de estudo e/ou de pesquisa, tal qual os pressupostos que estão presentes em uma "pesquisa-ação". São oportunidades que se abrem para que os professores aprendam um pouco mais com os colegas de ofício, tanto no tocante aos conhecimentos de conteúdo quanto em relação aos conhecimentos pedagógicos de conteúdo. Além do mais, tais conhecimentos precisam ser estudados, compreendidos e apropriados, desde o início da formação inicial de um futuro professor.

Entendemos que faz parte da natureza da prática pedagógica, a busca do antigo e do novo e o desejo de indagar, questionar e levantar hipóteses. Em suma, pressupostos necessários para se fazer pesquisa. Ademais, os professores recém formados precisam incorporar esses conceitos desde os primeiros dias de docência, uma vez que ser professor é aprender para todo o sempre, é formar-se todos os dias, é experimentar sem medo.

Mas, é preciso que o professor considere o quanto isso é importante para sua atuação docente ao longo de toda a sua trajetória formativa, a qual não se esgota com o tempo de exercício do magistério. É preciso que o professor compreenda e incorpore à sua formação continuada, que a sua trajetória formativa o irá acompanhar até a sua aposentadoria da função de professor efetivo de sala de aula. Uma formação de longa trajetória e sempre em continuidade.

E em função dessa percepção que o professor se assuma como um pesquisador porque seja professor. Assim, é preciso que o professor reflita acerca do fato de que ao ensinar ele está produzindo um conhecimento novo o qual, possivelmente, supere outro conhecimento que um dia também foi novo.

Daí a importância de o professor conhecer o conhecimento existente, sem deixar de vislumbrar a produção de novos conhecimentos ainda não existentes pois pesquisar implica em aprender e ensinar acerca do conhecimento existente e trabalhar para produzir um conhecimento ainda não existente.

Portanto, entendemos que a formação continuada de um professor perpassa idas e vindas crítico-reflexivas, segundo as quais as possibilidades nunca se esgotam 
em si. Ou seja, é sempre um ir e vir formado por uma infinidade de auto interrogações.

Tudo o mais vai ao encontro do que Freire (2013, p. 25) afirma: "ensinar não é transferir conhecimentos, conteúdos, nem formar é ação pelo qual um sujeito criador dá forma, estilo ou alma a um corpo indeciso e acomodado".

\section{REFERÊNCIAS}

BEACH, Richard; PEARSON, Donna. Changes in preservice teachers' perceptions of conflicts and tensions. Teaching \& Teacher Education, v. 14, n.3, p.337-351. 1998. Disponível em:

https://www.academia.edu/923655/Changes_in_preservice_teachers_perceptions_of_conflicts_and_ tensions. Acesso em: 19 nov. 2020.

BHABHA, Homi K. "The Third Space". In: RUTHERFORD, Jonathan. Ders. Identity: Community, Culture, Difference. London: Lawewnce and Wishart, 1990, p. 207-221.

CIRÍACO, Klinger Teodoro; MORELATTI, Maria Raquel Miotto; PONTE, João Pedro da. Os primeiros anos da docência e as dificuldades de professoras iniciantes que ensinam Matemática no interior do Estado do Mato Grosso do Sul. Perspectivas em diálogo: Revista de Educação e Sociedade, Naviraí MS, v.7, n. 12 (especial), p.51-70. 2019.

Disponível em: https://periodicos.ufms.br/index.php/persdia/article/view/9104. Acesso em: 19 nov. 2020.

FRANCO, Maria Amélia Santoro. Pedagogia da Pesquisa-ação. Educação e Pesquisa, São Paulo SP, v. 31, n. 3. set/dez. p.483-502. 2005.

Disponível em: https://www.scieo.br/pdf/ep/v31/n3/a11v31n3.pdf. Acesso em: 19 dez. 2019.

FREIRE, Paulo. Pedagogia da autonomia: saberes necessários à prática educativa. São Paulo: Paz e Terra. 2013.

HARGREAVES, Andy. Os professores em tempos de mudança: o trabalho e a cultura dos professores na Idade Pós-Moderna. Lisboa: Editora Mc Graw-Hill.1998.

MELO NETO, João Cabral de. Tecendo a manhã. In: A educação pela pedra. 1966. Disponível em: https://www.jornaldepoesia.jor.br/joao02.html. Acesso em: 18 jun. 2020.

ZEICHNER, Ken M. University-Based Teacher Education: Rethinking the Connections Between Campus Courses and Field Experiences in College-and University - Based Teacher Education. Journal of Teacher Education, v. 61, p. 89-99. 2010.

Disponível em: https://ccte.org/wp-content/pdfs-conferences/ccte-conf-2012-fall-zeichnerrethinking-connections.pdf . Acesso em: 21 nov. 2020. 